\title{
Universities, the Public Good, and the SDG 4 Vision
}

\author{
Stephanie Allais, Elaine Unterhalter, Palesa Molebatsi, Lerato Posholi \\ and Colleen Howell
}

The inclusion of higher education in the Sustainable Development Goal (SDG) targets signalled a significant shift from the focus on universal primary education in the Millennium Development Goal (MDG) framework. SDG 4 expresses a vision: 'Ensure inclusive and equitable quality education and promote lifelong learning opportunities for all' (UNGA, 2015b, p. 17). This raises many issues concerning what it means for universities, which are historically associated with elites, to be inclusive and equitable, and what roles universities could and should play in society. What does quality higher education mean in the context of developing societies, or wealthy but unequal societies, or a world with growing inequality and looming environmental disasters? Given that universities serve individual learning and confer degrees, can the orientation expressed in SDG 4 to 'lifelong learning opportunities for all' sit alongside acquisition of specific and not easily accessible knowledge and skills, and promotion of highly technical areas of research?

This chapter seeks to contribute to debate on these issues, and hence look closely at the higher education components of SDG Target 4.3, using research done on the public-good role of universities in four African countries: Ghana, Kenya, Nigeria, and South Africa. ${ }^{1}$ SDG Target 4.3 states: 'By 2030, ensure equal access for all women and men to affordable and quality technical, vocational and tertiary education, including university' (UNGA, 2015 b, p. 17). The central focus of the chapter is to introduce ways to understand key terms, such as access, affordability, quality, and equality, as applied to tertiary education. To do this, we draw on views of these concepts in relation to questions about the public-good role of universities. A notion of the public good is implicit in the general SDG vision in which education is mentioned in targets for food security, women's rights, decent work, health, and equalities. In the four African countries examined, the higher education sector is relatively small, but growing at a fast pace and confronted by a range of challenges around affordability, inequalities, and who defines quality. 
Contextual issues and complexities within each country call into question simply formulated targets for higher education worldwide, as envisaged in Target 4.3. While supportive of the spirit of the SDGs, which attempted to capture a vision in education that is transformative in scope and ambition (Sayed \& Ahmed, 2018; Unterhalter, 2019), we review some perspectives from different settings on how the SDG policy goals may be realised. We also highlight some of the conditions that enable or hinder the possibilities for the higher education sector to contribute to the public good and the achievement of SDG 4 .

Critiques of Target 4.3 have highlighted how difficult it is to assess. They question how it might guide policy given that its indicators are quite out of step with the text and aims of the target (King, 2017; Unterhalter, 2019). We concur with these comments. One of the problems with the indicators, and the direction they give to the target, is that they were developed at some distance from the contexts in which people have worked to interpret quality, equality, and public good in higher education. We discuss how indicators might help evaluate achievement of this vision and argue that for them to be effective they need to be highly context-sensitive. We propose an approach to constructing a public-good indicator that captures some of the less individualist notions of the benefits of higher education that have emerged in the four countries studied. This discussion draws out intrinsic and instrumental public-good roles of higher education and dimensions of availability, accessibility, and horizontality that are conditions for realising Target 4.3.

The chapter draws on data collected from interviews in the four countries in 2017 and 2018 to illustrate a number of conceptual points and arguments. The data were collected through interviews with a range of stakeholders associated with university systems in the countries - higher education staff, academic researchers and researchers focussed on higher education, ${ }^{2}$ student leaders, key officials in government and administrative bodies, employers, and representatives of organisations in civil society. Key informants were interviewed about their views of the relationship between higher education and the public good.

The first section discusses some of the key contextual features of African higher education systems that are important to thinking about the sDGs. This is followed by the development of our key argument through a discussion of some issues that emanated from interviews with a range of key informants in the four countries, which foreground debates about the meanings laid out in the target of 'equal access' to 'affordable' and 'quality tertiary education'. We then present some of our initial work toward developing an indicator for the public-good role of universities and reflect on how this could contribute to thinking about indicators for Target 4.3. In the conclusion, we draw out some 
of the implications of the analysis for different kinds of university systems and a more context-specific interpretation of Target 4.3.

The 2009 UnEsco World Conference on Higher Education in Paris adopted the resolution that higher education is a public good and gave special focus to the challenges and opportunities for the revitalisation of higher education in Africa (WCHE, 2009). The resolution was adopted in the context of an enormous expansion in university participation since 1990, including across the developing world and especially in sub-Saharan Africa (sSA). While these trends are important, equally important is the persistence, in most poor countries, of historical and contemporary inequalities that complicate this picture. These inequalities continue to have a profound influence on who gains access to and progresses through higher education, and the nature of the higher education provision that is in place.

Historically, in most poor countries, universities were the domain of the elite, who were being educated for religious, professional, managerial, and administrative jobs, usually linked to projects of colonial rule. In many countries, including in Africa, increases in the number of higher education institutions coincided with gaining independence, accompanied by some associated expansion in enrolments, often linked to ideas of a developmental state (Mkandawire, 2001) and national flagship institutions (Teferra, 2016). However, the numbers of students entering and graduating from these institutions were small and generally drawn from only the highest income groups and most powerful political formations - the 'elite of African society' (Mohamedbhai, 2014, p. 6). The imperative toward increasing enrolments and strengthening national universities was severely challenged in Africa in the 198 os by structural adjustment policies, which called for state resources to be directed away from higher education to other levels of education and for increased privatisation across most higher education systems (Samoff \& Carrol, 2003).

From the 199os, however, expanding economies, the aspiration to knowledge economies, growing secondary school enrolments, and widening political participation redirected attention back to higher education and associated initiatives to expand educational provision. Although a key 1995 World Bank policy paper emphasised the importance of primary education, paving the way for the de-emphasis on higher education in the Education for All (EFA) Dakar Framework for Action and the Millennium Development Goals (MDGs), in 1997 Joseph Stiglitz was appointed Chief Economist at the World Bank and 
published key works on the importance of developing countries' investment in scientific research and enhancing access to global public goods (Jones, 1997; Stiglitz, 1999). In the new millennium, higher education came to be seen by multilateral organisations and governments as a key feature of participation in the knowledge economy.

This trend toward higher education expansion was evident beyond Africa as well. UNESCO data show that in 2017 the global gross enrolment ratio (GER) for tertiary education was $38 \% .^{3}$ While this ratio shifts considerably across countries, from $9 \%$ in low-income countries to $77 \%$ in high-income countries, it reflects participation rates in tertiary education that have more than doubled over the last 20 years, with the fastest levels of growth having taken place across SSA (Darvas et al., 2017). However, this significant growth in tertiary enrolment in SSA has taken place from a very low base, so that in 2017 the GER for SSA was still only $9 \%$ (the same as the average for low-income countries), compared, for example, to $78 \%$ for North America and Western Europe, $51 \%$ for Latin America and the Caribbean, $51 \%$ for China, and $28 \%$ for India. In the four countries from which data for this study is drawn, significant growth is evident, although present levels of enrolment are still comparatively low within the global context. In 2016 Ghana and Kenya had GERs of $16 \%$ and $12 \%$, up from $6 \%$ and $3 \%$, respectively, in 2005. In South Africa, GER in higher education increased steadily from $14 \%$ in 2001 to $21 \%$ in 2016 . In Nigeria, the GER increased from 6\% in 1999 to $10.5 \%$ by 2010.

This expansion in enrolments, globally and within sub-Saharan Africa, has been enabled through a plurality of institutional forms. There has been growth in private and public provision, and mixtures of the two. In sub-Saharan Africa, private higher education has been especially significant in many countries, with these institutions becoming important contributors to increased student numbers and expanded higher education provision (Morley, 2014; Oanda \& Jowi, 2012). It is estimated that in sub-Saharan Africa the number of private universities and colleges, including for-profit and not-for-profit institutions, mushroomed from 24 in 1990 to 468 by 2007, reaching over 1,00o in 2014 (Darvas et al., 2017). Nigeria, for example, had three private universities in 2000. This number had increased to 50 by 2011 (Bamiro, 2016) and now stands at 79 (Nigeria, National Universities Commission, 2019). Different kinds of public and private tertiary-level institutions have emerged - universities, polytechnics, community colleges, and diploma-awarding institutions linked to professional practice, social development, and industrial, agricultural, or commercial forms of work.

While these trends all indicate a substantial expansion and diversification in higher education systems across SSA, inequity is also a feature of higher 
education systems across the region. This is revealed by the percentages of students entering the system who manage to complete their studies and graduate, and the persistence of social and economic inequalities in determining patterns of access to higher education (Darvas et al., 2017; Morley, Leach, and Lugg, 20o9; Oanda and Sall, 2016; Wangenge-Ouma, 2011), despite efforts by a number of countries to redress these historical imbalances (Schendel \& McCowan, 2016; Unterhalter \& Carpentier, 2010). Although researchers have drawn attention to limited data showing progression and completion in higher education in Africa (Darvas et al., 2017; Mohamedbhai, 2014), completion and graduation rates are low, with many students dropping out. Factors such as inadequate funding, myriad challenges related to poor schooling, language barriers, and inadequate levels of institutional support influence whether students manage to complete their studies (Adu-Yeboah, 2015; Breier, 2010; Mohamedbhai, 2014). Even in South Africa, with comparatively higher levels of enrolment, completion and graduation rates are low, and growth in enrolments 'has been accompanied by high failure and dropout rates', with $55 \%$ of students in universities in South Africa unlikely to complete their studies and graduate (South Africa, Council on Higher Education, 2013, p. 40).

Essack (2012) suggests that equitable access to higher education in Africa is undermined through a number of social, political, and economic factors that create and reproduce patterns of marginalisation and exclusion from the system. Socioeconomic status and household income are central to privileging 'the children of the wealthy and politically connected' (Darvas et al., 2017, p. $\mathrm{xvi}$ ) and ensuring that, despite organisational, national, and international policy imperatives to widen participation (Morley et al., 20o9), higher education across the region remains largely out of the reach of the poor. In fact, Oanda and Sall (2016) argue that, despite the dearth of reliable data, anecdotal evidence suggests that expansion may have widened disparities in access, with inequalities associated with gender, class, and geographical location remaining central to influencing access patterns.

Huge funding challenges faced by public higher education systems across the continent often amplify inequalities (Pillay, Woldegiorgis, \& Knight, 2017; Teferra, 2013). These are partly related to high levels of growth and rising costs in provision. While declining state funding of higher education is a global trend, in deeply resource-constrained environments with a range of competing demands on public budgets, this challenge is especially acute. For many institutions, the consequence is often constant 'financial emergency and uncertainty' (Wangenge-Ouma, 2011, p. 171) and the absence of a stable funding base as a necessary and essential condition for both equity and excellence (Teferra, 2013). Despite the strong calls for 'free' higher education 
by students and other stakeholders, traditional models of taxpayer-funded provision have come under scrutiny, with some researchers arguing that such models can only sustainably fund a small number of elite universities (Oketch, 2016).

In the discussions and meetings that led to the agreement of the SDGs, there were struggles over aspects of Target 4.3. These included equal access for all, affordability, and quality tertiary education, particularly in universities (Unterhalter, 2019). But there was a lack of precision about these terms. Did equal access mean all should have a right to enrol in university whether or not they had passed entrance examinations, or that entrance examinations should be abolished? Did affordable mean free higher education, and if so, for what percentage of the population? How was quality higher education to be defined, given the wide variety of university mission statements? How did quality fit with the idea of the 'developmental university', an institutional form pioneered in Africa, wholly concerned with addressing social, economic, political, and human development challenges (Coleman, 1986; Nkomo \& Sehoole, 2007)? How, given the difficulties of funding faced by universities and the complexities of measuring the outcomes of higher education in developing countries, was this vision to be financed and evaluated, particularly in the context of the narrowing of the quality agenda to mean only research intensity? (Boni, Lopez-Fogues, \& Walker, 2016; McCowan, 2016b, 2018; Regmi, 2015; Unterhalter, Vaughan, \& Smail, 2013). What were the benefits and drawbacks of seeking funding not just from historic sources such as fees and government grants, but financialised and repackaged loans, and large private sector investments? (Allais, 2017b; Mawdsley, 2018).

The global indicator for Target 4.3 focused on the "[p]articipation rate of youth and adults in formal and non-formal education and training in the previous 12 months, by sex' (see Appendix 2 of this book). This made no reference to affordability, quality, or the nature of universality, and therefore did not illuminate the target. Target 4.3 leaves much space for interpretation, and its broad priorities are not tied to any specific policies, implementation modalities, or financing arrangements. Nonetheless, the wording of the target and the selection of the global indicator suggest an approach to education as a 'quality good' that each individual needs to be able to access. We argue below that this interpretation goes against the vision of SDG 4 as outlined in the goal, which emphasises that quality is associated with inclusivity and equality. The public-good role of universities is part of an understanding of quality education. Universities' role in social development is not reducible simply to individual advancement. Considering the public-good role of universities also has implications for how affordability can be understood. 
The meaning of quality higher education is much contested (Lomas, 2002; Marginson, 2016; Schendel and McCowan, 2016). The ways in which quality, inclusion, and equality interlink and are realised in practice, particularly in contexts marked by histories of violence, dispossession, and struggles around justice, have been debated (Bhambra, Gebrial, \& Nisancioglu, 2018; Boni et al., 2016; Jansen, 2017; McCowan, 2016b; Unterhalter \& Carpentier, 2010). Some university rankings define quality in terms of inputs such as the level of academics' qualifications and selected outputs such as student completion time, graduate employment rates, or research intensity (Hazelkorn, 2012, 2015) and use these as metrics of accountability, performance management, or policy steering (Hazelkorn, Coates, \& McCormick, 2018). Tan and Goh (2014) define quality as being concerned with what students derive from acquiring a university education, although most ways of assessing this are linked to graduate employment or employability rather than wider social benefits. These conceptions treat higher education as a machine-like process and ignore questions regarding who the students attending university are, who the lecturers are, what is being taught, and how quality might connect with equality or wider projects for social transformation.

A contested and more open-ended view of quality was evident in the data we collected, and diverse views were expressed by academics, students, professional staff, and policymakers. For some, quality was linked with universities' limitation of access to those who achieved high scores in school leaving examinations. They argued that giving admission only to high achievers would ensure a high standard of qualifications and generate high levels of research insight. In Nigeria and Ghana, the view was expressed that this goal of producing high-end knowledge and elite graduates had been compromised through massification. A different view of quality, articulated by participants in all four countries, was about widening access, understood both as participation by a wider group of students and disseminating knowledge to wider publics.

In its current expression, Target 4.3 with its stress on quality, access, and affordability reads individualistically, with an emphasis on individuals obtaining quality knowledge and skills through access to higher education. The learning outcomes of university education are not specified, in contrast with Target 4.4 which mentions skills to be acquired for 'employment, decent work and entrepreneurship' (UNGA, 2015b, p. 17).

In all four countries, informants articulated a range of ways in which universities serve society more broadly than simply enhancing individual skill acquisition or enabling individuals to obtain degrees. Generally, these broader 
goals were articulated in terms of contributions to the development and betterment of society, national development plans, or addressing inequalities and exclusions. The acquisition of skills, and participation in higher education in general, are valuable in so far as they promote the well-being or development of society more broadly rather than for the sake of individual advancement. For example, a South African academic argued, "The role of higher education is to produce good quality graduates in those areas where the professionals in turn serve the country' (Interview, higher education researcher 1, 5 March 2018). But for some, this was not a simple input-output process, in which individuals who attended university would naturally enhance the public good, as those individuals were themselves enmeshed in relationships, which are the product of historic injustices.

Some interviewees acknowledged the individual benefits of higher education, with one arguing that universities in South Africa confer more private benefits and cannot be a public good because attending university primarily benefits the middle classes:

If we look at South Africa now and if we look at the data on returns on investment in higher education the wage premium of people with higher education is huge. It's one of the largest in the world. (Interview, higher education researcher 1, 5 March 2018)

Another academic expressed this more pessimistically:

It is statistically a public good just for the middle class, and it allows a small group of poor to get out of poverty, but firstly the percentage of poor that end up in higher education is miniscule: 2 to 3 percent, and the percentage of them that makes it is another 6o percent. (Interview, higher education researcher 2, 20 February 2018)

A more critical perspective was offered by a student leader at a large South African university, who argued that the public good is about benefitting the broader society:

As a society we miss that key thing about how we help each other. Rather than focussing on just an individual, how do we grow? The system is focussed on individuals, imparting certain skills. Rather than the bettering of broader society. (Interview, student leader, 23 January 2018)

Two themes thus seem to weave through the discussion of quality and public good in this data. The first is how private good, namely, advancement through 
quality education for individuals and selective groups, is connected to public good. The second is whether there might be ways to link notions of quality higher education and public good to more fully express an idea that they coconstruct decent and equitable societies.

This latter relationship was seen by many as sequentially linked with national development. For example, a representative from the Congress of South African Trade Unions (cosATU), one of South Africa's major trade union federations, argued that underfunding is preventing South African universities from contributing to developing public resources. Implicit in this is an idea of the role that universities could play in national development, were they to be better funded:

[Underfunding is] going to set us back many decades ... in terms of our own development because if we can't develop our own human resources, how do we expect to develop our country? How do we expect to mitigate problems when a major power station ... has to be built? We have to bring artisans from Malaysia and other countries whilst we are sitting with loads and loads of unemployment. How are we going to address those problems if we do not invest largely in education and training? (Interview, COSATU official, 22 November 2018)

A sequential form of analysis, linking private gains to public good, was raised in all four countries, including through arguments that universities need to produce graduates committed to advancing the good of society through their professional work. In this form, the argument also suggested universities needed to develop knowledge that contributes to society, addressing historical injustices such as colonialism. Community engagement was seen as a necessary part of quality education and the university achieving this public-good role. An official from the South African Department of Science and Technology argued:

The [rural] university should have programmes on monitoring water throughout the year ... You can't be doing work on things that are not contributing to development. ... You focus on local issues and through the local issues you deal with international issues because those issues could be relevant elsewhere. You begin to go national and global. (Department of Science and Technology interview, 1 December 2018)

This sense that universities' missions should be to contribute to solving local and national problems was articulated in a number of the interviews in all four countries and is one of the most common formulations of how quality higher education realises a form of public good. 
But a different formulation of this relationship suggested that higher education needs to co-construct ideas of the public good and quality with different constituencies in local, national, and global communities of practice and critique. For some, particularly in South Africa, the concept of Ubuntu, ${ }^{4}$ which has been applied to higher education (Letseka, 2012; Oviawe, 2016; Waghid, 2018), was linked to an expanded notion of quality.

This sense of using higher education as a setting to reformulate ideas of the public good, either critically, or through forms of practice, was raised in interviews across the four countries. However, local conditions meant that this co-construction sometimes was linked to very local struggles over resources, management, classroom practice, or approaches to student support. For example, students interviewed in Nigeria criticised the limited numbers and lack of preparation of lecturers, while the issue of decolonisation of the curriculum was a key concern in South Africa.

The claim that quality means co-construction of the public good could be seen as implying that quality education is not only measured intrinsically on academic standards or criteria internal to disciplines, but also in terms of what education can cultivate that is for society's betterment. Some reasoned that academic standards can in part be informed by this. The student representative council president of a university of technology in South Africa argued that one of the problems of the university was that

[t]he current system keeps knowledge essentially at the top. The doors to higher education have been opened, but the highest dropout rate is young black students from disadvantaged backgrounds. When we talk about free higher education and what \#Fees Must Fall is fighting for, we need students from townships and villages who can go back and tackle the issues, where it is very real to them, it's not just hypothetical. (Interview, 4 May 2018)

The cosatu representative emphasised the need for 'relevant' research that improves peoples' lives and for better communication of research findings, thus linking quality, public good, relevance, and public engagement. Here, university quality, autonomy, and public good co-construct each other. In these interpretations, the notion of quality extends considerably beyond what is learned and taught in universities, offering a wide terrain for putting Target 4.3 into practice in a direction that is oriented toward public good.

What these views of quality do not tell us, however, is how we would know whether or not a university is contributing in this way, or if its graduates are, and how measuring these aspects could or should be related to criteria within 
bodies of knowledge and the conduct of research (Muller, 2000; Young, 2008). There are also thorny issues about university autonomy. For example, some respondents saw aspects of quality as potentially highly compromised by the relationships and prescripts put in place in some private higher education institutions. Other interviewees emphasised similar concerns around the nature of the relationship between universities and governments.

A key feature emerging from the analysis of the data across the four countries was quality as a feature of collective possibility, not only of individual advancement. Widening participation in higher education could be a force for public and private transformation, including democratisation and personal and economic growth. But a small university system could also serve a state concerned with social services and improving the well-being of all in the society through the graduates it develops and the research it conducts. However, higher education, regardless of the size of the sector, can also contribute to the formation of elites and the practices that sustain them, and so accelerate corrosive forms of differentiation between social groups. Thus, what is coconstructed by a quality higher education system may be public bad, just as much as public good. Higher education can reproduce inequalities and arguably has done so throughout the world. This issue also surfaces in the text of SDG Target 4.3, around what meanings attach to the idea of affordable university education.

\section{Access to Affordable University Education}

Access and affordability are complex concepts which, like quality and public good, need to be understood in relation to particular contexts. What does affordable university education mean, and is it compatible with universal or even rising access to higher education in countries that have not managed to adequately fund universal primary education? Target 4.3 suggests affordability is a facet of quality but does not make clear whether university education is to be affordable for individuals, countries, or communities. Under what terms of social contract and evaluation of public good are these assessments made?

The inclusion of affordability in Target 4.3 is laudable, as it challenges the idea that university education is only a private good for those who can afford it. However, more and more countries are shifting to 'user fees' for university education, which place affordability under scrutiny. For some, this is a result of neo-liberal policy orientations and the shift away from universal, free service provision, but for all countries, funding mass higher education is a very different fiscal prospect compared to funding a small, elite higher education sector 
(Barr, 2004; Marginson, 2016). As the numbers of students accessing university education grows, funding becomes an area of difficulty and sometimes of crisis. One response to this has been the emergence of private institutions, partly due to increased demand for higher education and partly because higher education is a growing economic sector in its own right. In many countries, governments are implementing policies that are making higher education more and more expensive for individuals, although the extent of individual contributions and the mechanisms for individual payment differ between countries (Biffl \& Issac, 2002; Johnston, 2004). There is no easy policy solution to the problem of how much higher education should be funded from a country's public purse, and how else it should be funded.

Yet, the public-good role of universities cannot be separated from public access. In interviews in all four countries, key informants, most notably students, argued that a public good is a good that is publicly provided. As soon as higher education is treated as a commodity, it is more accessible to some members of the public than others. According to a South African trade union representative, a decommodification of higher education was needed in order both to achieve access and ensure that universities are serving the public:

If we roll back the markets, most of the issues that are derived from education can be accessed by the society. Almost everything is in the hands of the markets and there is a huge danger with that. (Interview, COSATU official, 22 November 2018)

Other informants argued that when university education is treated as a commodity, knowledge is produced to advance the interests of the market, and students become clients or customers purchasing services or products. The public-good aspect of quality associated with higher education was bound up with understanding knowledge and pedagogic relationships, not the notion of commodity. This suggests it is necessary to think about the co-construction of the notions of quality education as a public good, together with public provision of de-commodified knowledge, funded by the state, for example, through progressive tax regimes. However, this may be problematic in the African context (Allais, 2018a; Cloete, 2016; Jansen, 2017; Motala, Vally, \& Maharaj, 2018). One issue raised in the literature is fiscal erosion, which is apparent throughout Africa, both where university education is free and where it is not. The vice chancellor of a historically black university in a rural location in South Africa noted that while the public-good role of a university required widening access, the rapid expansion of the university he worked in had placed enormous burdens on institutional infrastructure, funding, student-staff ratios, and course 
quality. Similar comments were made by interviewees in the other countries, who stated that public higher education is underfunded, which, in the context of the levels of growth that have taken place, has had serious consequences for institutions and what they are able to provide. These comments indicate that access is not simply a matter of enrolment and that a key aspect of access requires posing the question: access to what? The social contract around public access to quality university education raises questions about affordability for institutions as well as individuals.

Informants in all four countries argued that those who benefit from higher education must pay for it. Thus, a view was expressed, linking affordability with individual benefits, and by implication, individual benefits with national development. For some, public access, as suggested in Target 4.3, meant a feebased system. Some saw imposing fees as compatible with expanding access, as long as there is sufficient financial support for those who need it.

Wider meanings of access were posited by informants, including epistemological access and forms of access that challenged and transformed injustice. For example, a trade unionist in South Africa argued that access entailed examining university entrance criteria, which, in their current form, undermined an inclusive idea of the public good.

A further refinement on ideas of access was articulated, casting affordability as more of a set of social issues in which money, time, and relationships of care were implicated. This was expressed in all four countries where informants emphasised that universities needed to be decent places to work and study, and only under such conditions could they provide settings to foster public debate and build connections with an immediate geographic community. Gender-based violence on campus was raised as a serious concern in all four countries. Interviewees noted that universities are more likely to have higher levels of gender-based violence than the wider society because of the power relations between students and staff:

Where else do you have those levels of power relations and those numbers? That unequal power relationship is magnified in this setting. For those universities that have residences there is global research that they present victim situations. You live in the space. If you are young you might not know the boundaries, you don't understand issues around consent.... Even the boundaries between lecturers and students are not well understood on both sides. We have never had a complaint yet but there are students who have offered sexual favours for marks. There are lecturers who offer marks for sexual favours. (Interview, university gender equity officer, South Africa, 25 July 2018) 
So, the power that a professor has over a student is an intense power, it's a power to define what happens for the rest of your life. It's extreme levels of power and being able to understand those kinds of powers and being able to deconstruct them and being able to make very clear choices about who is allowed to exercise that kind of power, right? Because as I said, it kills a student to be in an institution where the people who have a choice on whether you succeed or not in life are then abusive of that power and are allowed to be. (Interview, South African civil society activist, 22 November 2018)

A number of respondents in all four countries argued for the need to cultivate universities as places where public debate takes place to nurture cultural goods and public intellectuals. But, in contrast to this ideal, others pointed out that many universities are gated communities which exclude the public:

If you can't access the university physically then ... how are you going to do that? It must be a meeting place for people and ideas. (Interview, South African higher education researcher 6, 22 March 2018)

Stakeholders reasoned that it is difficult for universities to serve their immediate community when it is hard for members of a community to walk onto a campus. In South Africa, university leaders claim that they have fenced their campuses to protect staff and students from crime and violence pervasive in South Africa, an issue which is also of concern, to differing degrees, in the other countries. Some interviewees suggested that the status of a university was often signalled by its landscaped grounds and controlled access. But this too highlights the question of access to what, taking us back to the previous discussions on quality, and suggests other ways in which people can 'access' higher education, even if not through enrolment for degree or diploma programmes. So, for example, a student representative in South Africa suggested that his university contributes to the public good through the involvement of its management, particularly the vice chancellor, in the developmental and municipal issues of the town in which it is located. Some informants expressed a notion of engagement with the immediate material needs of the local community. In other words, access is not only immediate presence, but takes mediated forms, particularly sensitive to locale.

Access to higher education concerns the relationships between different levels of education systems. A common theme in the interviews across all the 
countries was that education needs to be improved at all levels - and that lack of quality schooling is a major threat to the viability of universities, including access, affordability, and quality. Quality primary and secondary education are central conditions of possibility for quality higher education. It is not surprising that a number of informants across the four countries talked of the need to fix schooling as a key to improving university education:

When I hear about the crisis in our schooling, ... many of those teachers were produced in the last 20 years. So, why are we having the same problems in our schools? Why can't our children read properly? And it's not rocket science. Why are we having the kind of abuse of girls and women in our schools? Why are girls feeling unsafe in our schools? All of those issues, tell me? ... What kind of teaching profession are we producing? ... $[\mathrm{T}]$ he same can be asked of other professions. (Interview, higher education researcher 1, 5 March 2018)

An expert on schooling in South Africa argued that universities are not able to do their jobs because they are finishing the job that the primary and secondary schooling system did not do because of inadequate teaching. A student leader echoed this, suggesting that the crisis in basic education is one of the contributing factors to the crisis in higher education:

You guys in universities are privileged already; our basic education is crumbling. ... We are privileged at university level; our basic education is my biggest concern. We are losing so many potential young people because of infrastructure in basic education, quality ... in basic education. (Interview, student leader at a small-town, historically white university, 11 December 2017)

In sum, the assumption in SDG Target 4.3 is that access to university education is about individual access, and that this is seen to be affordable by individuals, households, institutions, or nations. Target 4.b confirms this relationship with its stress on increasing the number of scholarships. Our research shows how access to quality university education is associated by some with ideas of inclusion and equity. This resonates with wider ideas about what is public, what is good, and how decommodification, conditions of work, and engagement with local needs are key dimensions of understanding equalities and inclusion. 
The interviews conducted with key informants shed light on some of the complexities of the meanings of affordability, access, and quality in higher education. But, as many commentators note, the indicators for Target 4.3 close down rather than illuminate these complexities, nuances, and perceptions of public good and collective possibility (King, 2017; McCowan, 2018; Unterhalter, 2019).

Target 4.3 is currently to be evaluated by three indicators (UNGA, 2015b, p. 17): 4.3.1. Participation rate of youth and adults in formal and non-formal education and training in the last 12-months, by sex;

4.3.2. Gross enrolment ratio for tertiary education by sex;

4.3.3. Participation in technical-vocational programmes (15-24 years old), by sex.

These indicators suggest that the expansion of enrolment is the most necessary development to capture some of the 'sense' of Target 4.3. But many elements of the focus of the target - on inclusion, affordability, and quality - are missed. None of the three indicators deals with quality. A criticism of the GER for tertiary education is that it is not sensitive to the age range of people participating in higher education, focusing on participation within the postsecondary school age range of a population. So, this measure does not effectively illuminate what role access to university is playing for different demographics, which is linked to histories of inequality. Existing metrics are not measuring the intersections of inequalities or the forms of intervention needed to secure equity.

To attempt to start filling these gaps, our project has proposed a dashboard of indicators through which the complexities and nuances raised by stakeholders can be made visible. It works as a visual representation of the components of our indicators 'at-a-glance'. This helps to better capture the public-good character of universities by embedding the indicators in as much context as possible. A dashboard offers a practical way of looking at data across countries, as well as of organising qualitative and quantitative data in a meaningful way.

In developing the dashboard, we have drawn on an evaluation of existing quantitative metrics and analysis of the qualitative data we collected. The interview data were coded in terms of the main ideas of stakeholders regarding higher education and the public good. These ideas included the following: higher education is only a public good under certain conditions (e.g., when there is a conducive social contract); the public good is strongly bound to the idea of a public sphere(s) and that the university constructs these spaces (e.g., through the advancement of cultural and social goods); higher education for the public good serves the needs of society at large (e.g., by advancing human 
development); and there are private and public benefits to higher education, although the private can sometimes be interwoven with the public. In terms of these views from stakeholders, conditions that enable or hinder the capacity of institutions to contribute to the public good - the conditions of possibility - were identified from the data. Some were explicit, and others implicit. These conditions were either 'external' - relating to the necessary conditions in society but outside of the higher education sector in order to facilitate the public-good role of universities - or 'internal' - relating only to the conditions necessary in the higher education sector. Some conditions of possibility were characterised as both internal and external.

Figure 6.1 provides an illustration of the proposed public-good dashboard. The first conceptual consideration is a distinction between the intrinsic and the instrumental public-good roles of higher education taken from the literature (Unterhalter et al., 2018). The intrinsic refers to the value of education as an end in itself and the experience of education for its own sake, while the instrumental has to do with higher education's value as a socially responsive institution. The interview data were organised using codes related to one of

\section{Intrinsic Public-Good Roles}

Access
- Gross enrolment ratio
- Completion and throughput
rates
- Disaggregation: gender,
race/ethnicity; socioeconomic
background; rural/urban
- Balance between public and
private enrolments
-Stratification

Funding and provision
- Level of funding (percent of
GDP and of government
expenditure)
-Balance of public/private
funding
-Disparities between institutions
- Student/staff ratio
- Staff profile
-Disciplinary spread

Deliberative space
-Academic freedom
-Appointment of officials
- Representation (governing
councils etc.)
- Student participation
-Dialogical pedagogy

\section{Instrumental PublicGood Roles}

Graduate destinations
-Rates of employment, types of
employment, public and private
sectors
- Social enterprise/
entrepreneurship/other
destinations
-Disaggregation by social group
- Tax contribution
- Income inequalities
-Political participation and civic
engagement

Knowledge production

- Research activity

-Publications (Web of Science/ Scopus)

-National/local/open access publications

-Number of researchers per million population

- Concentration/diffusion of knowledge production
Community engagement

-Number and type of outreach projects

-Community representation in university bodies

-Availability of courses for public

-Public communication of research

-Community use of university facilities

FIGURE 6.1 Dashboard for a public-good indicator 
the two, although some stakeholders viewed the intrinsic and instrumental roles as overlapping and/or sometimes inseparable.

Also emerging from the literature and considered in the dashboard is McCowan's (2016a) framework for access, which uses three dimensions to open up the question, access to what? These are 'availability', which refers to the capacity of institutions to absorb incoming students (i.e., sufficient places so that all members of society who so desire, and who have a minimum level of preparation, can participate in higher education); 'accessibility', referring to which groups can access higher education, and how academic performance tests and tuition fees become the mechanisms determining who gets into university; and lastly, 'horizontality', which is concerned with stratification in higher education and hierarchies of prestige and quality between universities - where disadvantaged students are confined to lower quality institutions.

Out of these categories arise the six indicators displayed in Figure 6.1, labelled either intrinsic or instrumental, to make up the public-good dashboard. They cover access, funding and provision, deliberative space, graduate destinations, knowledge production, and community engagement. These categories are taken from the literature defining the key pathways through which higher education contributes to the public good in society as well as the views of stakeholders in the four African countries studied.

Only some of the indicators suggested by interviewed stakeholders can be incorporated into the dashboard, given the information resources currently available. Benchmarking tools relating to community engagement exist. Based on institutional data, these include the Higher Education Funding Council for England's regional benchmarking tool, the Russell Groups' Higher Education Community Engagement Tool in the UK, the Carnegie Foundation's Documentation Framework (2008) in the US, and the tool under development by the Conference on Community Engagement in Higher Education through the Council on Higher Education and the Joint Education Trust in South Africa (Olowu, 2012). Based on these kinds of tools for community engagement, we can see the possibility of including a 'deliberative space' indicator and asking institutions to self-report on that area. The 'deliberative space' overlaps conceptually with stakeholders' general view of the public sphere as involving critical dialogue not only within the university itself, but at what stakeholders call the 'popular level' (i.e., the community).

The dashboard under development is only a starting point to begin identifying the elements of access to quality higher education that serves a wider social transformation agenda. Our intention is not to suggest that this publicgood indicator is exhaustive or without problems, but to contribute to thinking about strengthening SDG Target 4.3. 
The question of measuring SDGs remains high on the agendas of many, so much so that the Times Higher Education (THE) World University Rankings are in the process of developing an SDG ranking system. The aim will be to assess universities' contributions to the SDGs. Metrics currently being explored include the number of graduates in health professions, the proportion of women in senior academic positions, and policies and practices regarding employment security (Bothwell, 2018). While this may look like a step forward in measuring the social justice role of universities, it is likely to present problems similar to those associated with previous $T H E$ rankings - not least because it remains a ranking system. Unlike the forthcoming THE SDG metrics, the dashboard under development through our research project is not a ranking system, but an assemblage of information that can be used by institutions and national planning systems. So, despite many possible limitations, including limited availability and reliability of data, the need to explore counterfactuals to examine the nature of contextual variables and formations of conditions of possibility, we suggest the dashboard can make a contribution toward new ways of measuring the previously unmeasured in higher education. As such it can help crystallise goals to which national systems of higher education can aspire.

Two important insights emerge from our research on higher education quality, access, and affordability in relation to the SDG Target 4.3 framework.

The first is that quality education in relation to the public-good role of universities requires movement away from an individualist focus toward the common good, to approach quality in higher education in terms of universities' contribution to wider society. The phrasing of Target 4.3, concerning 'equal access of all women and men to affordable quality higher education', allows for an interpretation that excludes this socially located sense of access to the benefits of institutions. The target can be interpreted to mean that the primary purpose of all universities is to ensure access - narrowly understood as enrolment - for all. But striving for this simplistic and individualistic goal has raised serious funding problems for most countries and could undermine other crucial roles through which universities contribute to society and which the wider framing of SDG 4 implies.

The analysis emerging from the data we collected highlights that higher education is an intrinsic good, and one that all nations should strive to provide. But what was stressed is that it is not only or even primarily an intrinsic individual good. We suggest that expanding higher education participation rates 
will not jumpstart social development. Education is a goal of social development, but in the absence of economic development, if university education becomes unaffordable, wider social development goals are placed in jeopardy.

Our findings make apparent that achieving quality higher education is linked to a range of contextual processes. In many interviews, stakeholders raised different conditions of possibility for higher education to serve the public good, and hence to be evaluated as quality. If we think of quality in terms of the public good, the conditions of possibility show how we can achieve quality education by suggesting what conditions need to be in place for higher education, whatever the form of access, to contribute to the public good.

The second insight is that this approach to quality in higher education implies measuring outputs of education somewhat differently from conventional metrics. Measurements of quality that simply tally the number of graduates produced do not reveal the significance of graduation and how graduates might contribute to a form of public good. Our proposed dashboard suggests indicators more in line with the roles for higher education associated with inclusion and equality.

Our discussion suggests interpreting Target 4.3 through the lens of the overarching SDG 4 goal with its stress on inclusion, equality, and lifelong learning, drawing out their public-good dimensions, rather than through a narrow mesh of indicators that highlight only individual access and participation. Given the many vested interests associated with an 'individual advantage' reading of access and inclusion, we consider this may well be one of the most contested issues in relation to the SDG targets. The insights we have reported from research in four African countries suggest that co-constructions of quality, inclusion, and equity in higher education are both desirable and possible.

\section{Notes}

1 The chapter draws on research conducted as part of the ESRC, Newton Fund, NRFfunded project 'Higher Education, Inequality and the Public Good: A Study in Four African Countries'. We are grateful to our fellow researchers Christine Adu-Yeboah, Samuel Fongwa, Jibrin Ibrahim, Tristan McCowan, Louise Morley, Mthobisi Ndaba, Siphelo Ngcwangu, Ibrahim Oanda, and Moses Oketch for the discussions and insight that have been associated with our three years of work together collecting and analysing data and developing a perspective on issues relating to inequalities and the public good that have informed our reflection on SDG 4 in this chapter.

2 In the citations from interviews below, we distinguish between academic staff representatives and academic experts who research higher education. 
3 UNESCO defines this as the total enrolment in tertiary education, regardless of age, expressed as a percentage of the total population of the five-year age group following on from secondary school leaving. This age group may differ in different countries but is usually around 18 to 22 years. All data cited in this paragraph are drawn from the UNESCO Institute for Statistics, http://uis.unesco.org, accessed ${ }_{15}$ February 2018.

4 Ubuntu is a concept used to capture the sense that 'I am because we are', which is central particularly to sub-Saharan African ethics and morality. The gist of Ubuntu is the connectedness and collaborations in human relationships, so that humanity is defined by the interconnections and relationships one has with other people. Ubuntu originates from the proverbial expressions in Sotho languages, 'Motho ke motho ka batho babang' or in Nguni languages, 'Umuntu ngumuntu ngabantu' (Letseka, 2012; Le Grange, 2012), translated as 'a person is a person through their relationship to others' (Swanson, 2015, p. 34; Mboti, 2015, p. 127; Metz \& Gaie, 2010, p. 275). Ubuntu can be understood as trying to capture a communitarian essence of what it is to be human. 